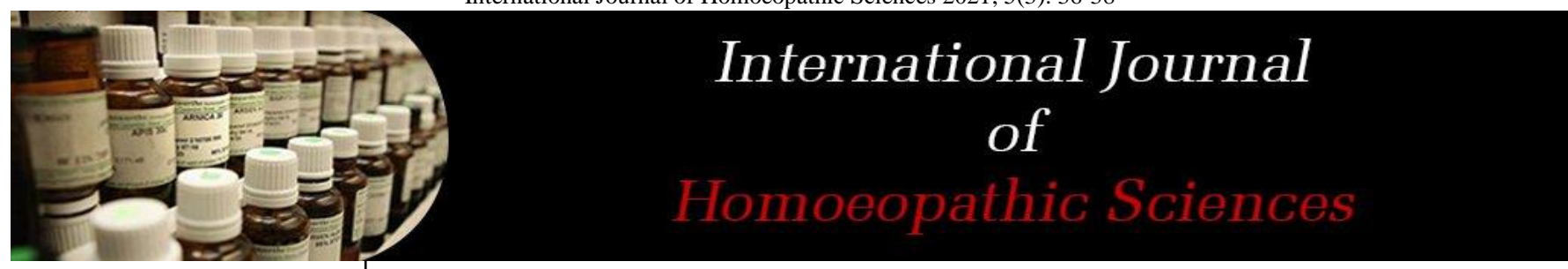

E-ISSN: 2616-4493 P-ISSN: 2616-4485 www.homoeopathicjournal.com IJHS 2021; 5(3): 36-38

Received: 03-03-2021

Accepted: 29-04-2021

Dr. AT Senthilkumar Professor, PG Guide, Head of the Department, Department of Homoeopathic Materia Medica, Vinayaka Mission's Homoeopathic Medical College and Hospital, Constituent College of VMRF (Deemed to be University), Salem, Tamil Nadu, India

Dr. G Angelin Jeba Post Graduate Student, Department of Homoeopathic Materia Medica, Vinayaka Mission's Homoeopathic Medical College and Hospital, Constituent College of VMRF (Deemed to be University), Salem, Tamil Nadu, India
Corresponding Author: Dr. AT Senthilkumar Professor, PG Guide, Head of the Department, Department of Homoeopathic Materia Medica, Vinayaka Mission's Homoeopathic Medical College and Hospital, Constituent College of VMRF (Deemed to be University), Salem, Tamil Nadu, India

\section{Epistaxis nose-bleed}

\section{Dr. AT Senthilkumar and Dr. G Angelin Jeba}

DOI: $\underline{\text { https://doi.org/10.33545/26164485.2021.v5.i3a.402 }}$

\section{Abstract}

Epistaxis is common condition of nose. It is often unilateral or bilateral. It's rarely seen in infants and customary in males. Epistaxis could also be a symbol and not a disease and an attempt should find any local or constitutional cause. It's often related to changes in temperature, humidity and in atmosphere. The causes of epistaxis are often divided into local, systemic, environmental, medication within the majority of some cases are idiopathic. Epistaxis are often classified by its anatomical location into anterior and posterior epistaxis. Anterior epistaxis is more common than posterior epistaxis. Flexible or rigid endoscopic examination, anterior and posterior endoscopy is beneficial for diagnostic purpose. Epistaxis is well managed with homoeopathic medicine.

Keywords: Epistaxis, homoeopathy therapeutics

\section{Introduction}

In 1793 nose bleed, the term 'Epistaxis' is Latin derived from the Greek epistazein (epiabove, over; stazein - to let fall in drops) ${ }^{[9]}$. Carl Michel, James Little, and Wilhelm Kiesselbach were the primary identified the nasal septum ${ }^{[2]}$. It is often unilateral or bilateral. Bleeding from inside the nose is called epistaxis ${ }^{[2]}$. Blood flow down into stomach and cause nausea and vomiting. In more additional severe cases blood may begin from the both nostrils. If bleeding is so significant it causes low blood pressure ${ }^{[1]}$. Its incidence is difficult to assess but it's expected that approximately $60 \%$ of the population are going to be suffering from epistaxis at some point in their life time. Epistaxis appears more often in males than in females. This is because the males are more frequently involved in outdoor activities like sports and interpersonal violence. It often present as emergency condition. The blood supply to the nasal cavity is by sphenopalantine artery so it's called as artery of epistaxis ${ }^{[2]}$.

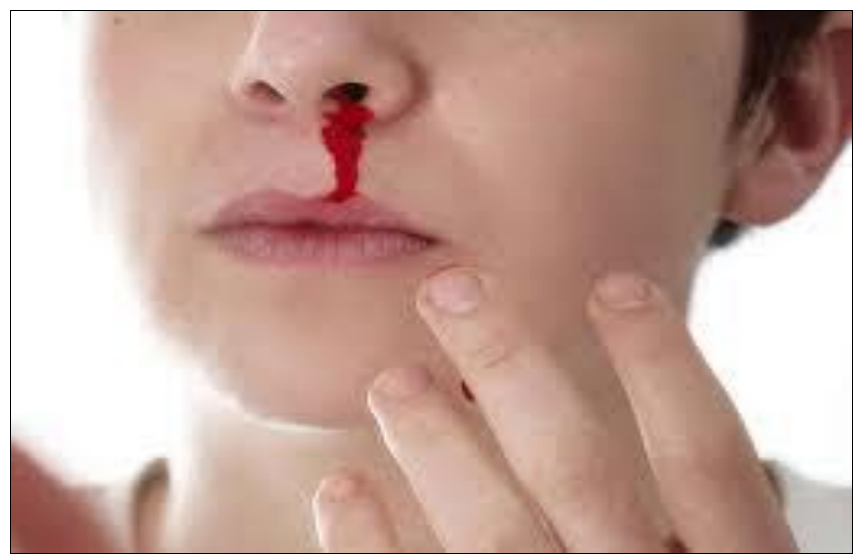

Fig 1: laterality the bleed

\section{History and Evaluation ${ }^{[2,11]}$}

The history should be included with the duration, severity, frequency, laterality the bleed, inciting event, and interventions provided before the seeking attention. Enquire about anticoagulant, aspirin, NSAID, and topical nasal steroid use. History taking is extremely important to understand about particularly if there's any case history of coagulopathy, vascular disease and about drug and alcohol use. The patient should asked about the bleeding presentation and previous bleeding episodes and currently taking any medications like herbal 
and home remedies.

Prepare proper equipment and proper personal protective equipment before beginning physical examination. Equipment must include nasal speculum, bayonet forceps, headlamp, suction catheter, packing, silver nitrate swabs, cotton pledgets, and topical vasoconstrictors and anesthetic. Have patient in seated position during an exam chair in a room with suction available. Carefully insert the speculum and slowly open the blades to ascertain the bleeding site. A headlight allowed for hands-free illumination, and clot may need to suction from the cavity to spot the bleeding source.

\section{Sites of epistaxis ${ }^{[4,12]}$}

- Little's area

- Above the extent of middle turbinate

- Below the extent of middle turbinate

- Posterior a part of cavity

- Diffuse

- Nasopharynx

\section{Causes of epistaxis ${ }^{[2,14]}$}

The explanations for epistaxis are often divided into local, systemic, environmental, medications or, within the bulk of cases idiopathic. Nose blowing habit, excessive coughing and in chronic obstructive pulmonary disease (COPD), straining in constipation and benign prostatic hyperplasia $(\mathrm{BPH})$, lifting heavy objects are the aggravating factors for the epistaxis. Environmental factors like humidity and allergens also must be considered.

Table 1: Local causes of epistaxis, Systemic causes of epistaxis

\begin{tabular}{|c|c|}
\hline Local causes of epistaxis ${ }^{[20]}$ & Systemic causes of epistaxis \\
\hline Trauma (Digital, Nose & 1. $\quad$ Age \\
\hline blowing, Blunt, Finger & Hypertension \\
\hline nail trauma, Injuries of & Hemophilia \\
\hline nose, Violent sneeze) & 4. Leukemia \\
\hline 2. Mucosal dehydration & 5. Coagulopathy \\
\hline (Deviated septum, Arid & 6. Thrombocytopenia \\
\hline environment) & 7. Alcohol \\
\hline 3. Infections (Rhinitis, & 8. Platelet dysfunction \\
\hline Sinusitis, Autoimmune & 9. Renal disorder \\
\hline disorders, Rhinitis sicca, & 10. Cancer chemotherapy \\
\hline Environmental irritants) & 11. Liver disease (e.g. cirrhosis) \\
\hline $\begin{array}{l}\text { 4rritants (e.g. Cigarette } \\
\text { smoke) }\end{array}$ & $\begin{array}{l}\text { 12. Hereditary Hemorrhagic } \\
\text { Telangiectasia }\end{array}$ \\
\hline 5. Neoplasia & 13. Drugs \\
\hline $\begin{array}{ll}\text { a. Benign (Inverted } \\
\text { papilloma, Juvenille } \\
\text { nasopharyngeal } \\
\text { angiofibroma) }\end{array}$ & 14. Acute general infection \\
\hline $\begin{array}{ll}\text { b. } & \text { Malignant } \\
\text { (Nasopharyngeal } \\
\text { carcinoma). }\end{array}$ & \\
\hline 6. Foreign bodies & \\
\hline 7. Deviated nasal septum & \\
\hline
\end{tabular}

\section{Classification $^{[4,18]}$}

- Epistaxis are often classified by its anatomical position.

- There are two kinds of classification. They are:

- Anterior epistaxis

- Posterior epistaxis

\section{Anterior epistaxis}

It's more common than posterior one. It mostly occur in Little's area or anterior a neighborhood of lateral wall. The blood supply of anterior epistaxis is from internal and external carotid artery arteries. Mostly occurs in children and young adults due to trauma. It is often easily controlled.

\section{Posterior epistaxis}

It's less common. In posterior epistaxis it's difficult to localize the bleeding point. The arterial supply is sphenopalantine artery.

\section{Symptoms}

The signs and symptoms of a nosebleed include ${ }^{[3,8]}$

- Bleeding from either or both nostrils

- A bloody sputum

- Jaw pain

- Nasal congestion

- Irregular heart beats

\section{Diagnosis $[2,13]$}

- Anterior Rhinoscopy - usually it spots the bleeding area, prominent anterior septal vessels, ulceration with or without crest.

- Posterior Rhinoscopy - is difficult, but it's helpful in mild epistaxis, blood stained nasal discharge in cases of rhinosporidiosis within the world of nasopharynx or fungal sinusitis.

- Nasal Endoscopy is beneficial to aim spot the situation. It's useful in identifying and treating the bleeding point.

- Imaging studies like X-ray, CT scan, and Digital subtraction angiography is useful in identification of bleeding vessels and helpful in ruling out infective traumatic and neoplastic conditions.

- There also some Haemotological investigation in nose bleed. They are:

1. Complete blood count that include Clotting and bleeding profiles.

2. Blood grouping and cross matching.

3. Blood counts including total platelet count.

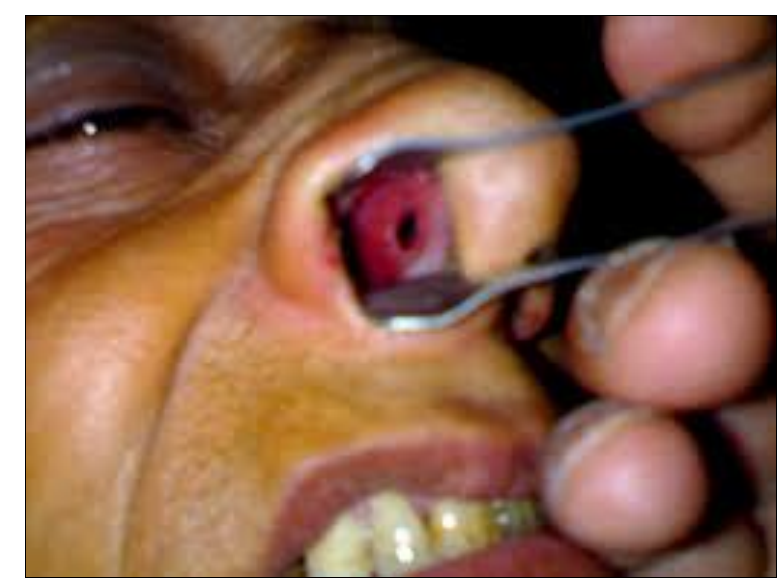

Fig 2: heavy bleeding

Complication $^{[8]}$

- Aspiration

- Sinusitis

- Hypovolemia in heavy bleeding

- Cerebral abscess is extremely uncommon

- Haemorrhagic shock

- Septal pressure necrosis

Prevention ${ }^{[10]}$

- Avoid nose picking and keep fingernails short. 
- Should not blow nose often when blowing it should be done very gently.

- Avoid excessive alcohol drinking and smoking.

- Avoid heavy outdoor activities like sports.

Homoeopathic management ${ }^{[5-7,15-17]}$ Arnica montanna

It's indicated in trauma epistaxis. Its haemorrhagic remedy and it are often utilized in short intervals. Nose bleed after every fit of coughing after washing face, dark fluid blood. It's mainly indicated for sore lame bruised feeling within nose that gets sudden epistaxis. Nose bleed during which blood is dark and fluid within nose has sore feeling.

\section{Aconite}

Copious epistaxis with fullness of head. Pain at the root of the nose. Throbbing pain in nostrils ${ }^{[19]}$.

\section{Carbo veg}

Frequent and continued nosebleed, especially within the morning and forenoon, or when pressing at a stool, great paleness of the face during and after the bleeding. Patients feel better in cold air.

\section{Ferrum phos}

This medicine is suited to pale anemic subjects with violent congestion of the nose. Bleeding is bright red in colour with headache and cold. Specially indicated in epistaxis due to sunstroke, anemia, and high blood pressure.

\section{Ipecac}

This remedy suits well in cases of epistaxis with characteristic symptoms of persistent nausea and vomiting. Epistaxis with bright red blood which is profuse. It's indicated in fat children and adults who tend to catch a cold when the weather is warm and moist. Epistaxis with a clean tongue.

\section{Melilotus}

Epistaxis with bright red blood and this relieves sick headache in melilotus. Congestion and hemorrhage is present in this drug. Hard clinkers in the nose. Nose block, dry must breathe through the mouth. Cases requiring mellilotus suffers from violent throbbing congestive headache.

\section{Secale}

Epistaxis with great prostration and drawn features. Congestion of the head, Catarrh, Menstrual difficulties, Debility, Ill effects of injuries.

\section{Phosphorous}

Epistaxis with fan like motion of nostril. Foul smelling odour from the nose. Periostitis of nasal bones.

\section{Conclusion}

Over the past years there is a significant option available for management of epistaxis. Homoeopathic medicines have its significant role in the management of epistaxis. Along with homoeopathic medicines the patients are advised to do ice or cold pack application that arrest the bleeding by vasoconstriction.

\section{Reference}

1. Nose bleed - Wikipedia [Internet]. En.wikipedia.org. Available from:

https://en.wikipedia.org/wiki/Nosebleed.

2. Hazarika P, Nayak DR, Balakrishna R. Textbook of Ear, Nose, Throat and Head \& Neck Surgery (theory, Clinical \& Practical). CBS Publishers \& Distributors 2007.

3. Nosebleeds: Causes, treatment, and home remedies [Internet]. Medicalnewstoday.com. Available from: https://www.medicalnewstoday.com/articles/164823.

4. Dhingra PL, Dhingra S. Diseases of Ear, Nose and Throat-eBook. Elsevier India 2017.

5. Boericke W. Pocket Manual of Homoeopathic Materia Medica \& Repertory:Comprising of the Characteristic and Guiding Symptoms of All Remedies (clinical and Pahtogenetic [sic]) Including Indian Drugs. B. Jain publishers 2002.

6. Homeopathic Medicine for Nose Bleed - Rajneesh Kumar Sharma [Internet]. Hpathy.com. Available from: hpathy.com/cause-symptoms-treatment/homeopathynose-bleed-epistaxis

7. Lilienthal S. Homoeopathic therapeutics. Boericke \& Tafel 1907.

8. Epistaxis: Practice Essentials, Anatomy, Pathophysiology [Internet]. Emedicine.medscape.com.

9. Epistaxis: Origin and meaning of epistaxis by online etymology dictionary

10. [Internet]. Available from: osmosis.org/answers/epistaxis.

11. Kucik C, Clenney T. Management of Epistaxis [Internet]. Available from: Aafp.org

12. Epistaxis (nose bleed) [Internet]. Available from: Fr.slideshare.net

13. Parajuli R. Evaluation of Etiology and Treatment Methods for Epistaxis: A Review at a Tertiary Care Hospital in Central Nepal.

14. Maqbool M, Maqbool S. Textbook of Ear, Nose and Throat Diseases. JP Medical Ltd 2013.

15. Homeopathy S. Star Homeopathy | Homeopathy Treatment for Epistaxis.

16. Murphy R. Nature's Materia Medica. Blacksburg, Lotus Health Institute 2006.

17. Phatak SR. Materia medica of homoeopathic medicines. B. Jain Publishers 2002.

18. Peterkin H. A Manual of Diseases of the Nose, Throat, and Ear. By EB Gleason MD, LLD Philadelphia and London: WB Saunders Company. 1924. The Journal of Laryngology \& Otology 1925;40(5):351-2.

19. Adi BS. Effective of Hydrastis in Treatment of Cholelithiasis- An Observation Study. International Journal for Advance Research and Development 2017;2(10):65-9.

20. Homeopathic Treatment, Medicines, Remedies for Nosebleed: Types, Effectiveness, and Risks [Internet]. Available from: myUpchar.com

21. Packard FR. Text-book of diseases of the nose, throat and ear: for the use of students and general practitioners. JB Lippincott Company 1909. 